\title{
Ohra ja kaura karitsoiden ruokinnassa
}

\author{
Riitta Sormunen-Cristian ${ }^{1)}$ ja Lauri Jauhiainen ${ }^{2)}$ \\ ${ }^{1}$ MTT, Kotieläintuotannon tutkimus, Eläinravitsemus, 31600 Jokioinen, riitta.sormunen-cristian @mtt.fi \\ ${ }^{2}$ MTT, Tutkimuspalvelut, Tietopalvelut, 31600 Jokioinen, lauri.jauhiainen @mtt.fi
}

\section{Johdanto}

Ympärivuotisessa karitsoinnissa tilalla joudutaan suunnittelemaan myös karitsoiden talvikauden ruokinta. Sisällä lihakaritsat kasvatetaan useimmiten voimaperäisesti kotoisella viljalla. Ohran ja kauran paremmuutta ruokinnassa sekä jauhamisen tai litistämisen vaikutusta syöntiin ja kasvutuloksiin on usein pohdittu kasvattajien keskuudessa. Koska kotimaisia tutkimustuloksia aiheesta ei ollut, järjestettiin MTT:n Kuuman lampolassa tutkimus, jonka tarkoituksena oli selvittää viljan prosessoinnin vaikutusta karitsoiden rehunsyöntiin, kasvuun, terveyteen ja lihantuotantoon.

\section{Aineisto ja menetelmät}

Tutkimus koostui kolmesta samanlaisesta, peräkkäisinä vuosina tehdystä karitsoiden ruokintakokeesta. Vertailtavina olivat ohra ja kaura jyvinä, litistettynä ja jauhettuna.

Karitsoita oli yhteensä 192. Kokeen alussa karitsat painoivat keskimäärin 20,6 kg (s.d. 4,5 kg) ja olivat keskimäärin 74 päivän (s.d. 13,0 pv) ikäisiä. Eläimistä puolet oli pässi- ja puolet uuhikaritsoita. Kummastakin sukupuolesta puolet oli puhtaita suomenlampaita ja puolet risteytyksiä texelin kanssa. Karitsat jaettiin sukupuolen, rodun, elopainon ja iän perusteella kuuteen samanlaiseen ryhmään. Ryhmä 1 sai ohraa jyvinä, ryhmä 2 ohraa litistettynä, ryhmä 3 ohraa jauhettuna, ryhmä 4 kauraa jyvinä, ryhmä 5 kauraa litistettynä ja ryhmä 6 kauraa jauhettuna. Karitsat olivat kokeessa vieroituksesta teurastukseen keskimäärin 85 päivää.

Syönnissä pyrittiin mahdollisimman suureen kuiva-aineen syöntiin ja niinpä viljaa annettiin $80 \%$ päivittäisestä maksimikuiva-aineen syönnistä (Owen 1976, s. 203). Metabolista elopainokiloa $\left(\mathrm{kgW}^{0,75}\right)$ kohden ilmaistuna määrä oli $72 \mathrm{~g}$ kuiva-ainetta $(\mathrm{ka}) / \mathrm{kgW}^{0,75} /$ päivä. Väkirehumäärä vastasi 800 g viljaa 20-kiloiselle karitsalle ja noin 1350 g 40-kiloiselle karitsalle päivässä. Väkirehun lisäksi karitsat saivat vapaasti timotei (Phleum pratense L.) - nurminataheinää (Festuca pratensis Huds.), kivennäistä $(\mathrm{Ca}: \mathrm{P}=2,2: 1)$, suolaa ja vettä. Jotta karitsoiden kalsium : fosfori -suhde ja kalsiumin saanti olisivat olleet ravinnontarvesuositusten mukaisia (Tuori ym. 2000), annosteltiin kullekin karitsalle väkirehun joukkoon 12-15 g kalsiumkarbonaattia $\left(\mathrm{CaCO}_{3}\right)$ päivässä.

Rehuista tehtiin virallinen rehuanalyysi. Energia-arvot laskettiin muuntokelpoisena energiana (ME) ja valkuaisarvot ohutsuolessa imeytyvinä aminohappoina (OIV, Tuori ym. 2000). Rehujen in vivo -sulavuus määritettiin seitsemällä aikuisella pässillä kahtena latinalaisena neliönä.

Tilastolliset analyysit tehtiin SAS-ohjelmiston MIXED- ja FREQ -proseduureilla. Valituissa tilastollisissa malleissa otettiin huomioon koe, kasvilaji, käsittely, sukupuoli ja tarvittavat yhdysvaikutukset. Koe -tekijä toimi varianssianalyysimalleissa satunnaisena vaikutuksena eli kolmen kokeen ajateltiin olevan otos isommasta kokeiden ja koevuosien populaatiosta. Näin ollen saadut tulokset voidaan yleistää koskemaan koko populaatiota eikä vain valituksi tulleita karitsoita ja ohra- ja kauraeriä. Kasvilajeja ja käsittelyitä vertailtaessa virheterminä käytettiin kasvilaji x käsittely x koe -yhdysvaikutusta. Loppupainoa analysoitaessa alkupaino otettiin kovariaatiksi.

\section{Tulokset ja tulosten tarkastelu}

Litistäminen ja jauhaminen eivät parantaneet ohran tai kauran orgaanisen aineen sulavuutta. Ohran raakavalkuainen suli parhaiten jauhettuna. Kaura sisälsi enemmän raakakuitua kuin ohra (104 vs. $51 \mathrm{~g}$ /kg ka) (Taulukko 1).

Syönti. Käsittelyn vaikutus väkirehun syöntiin oli samanlainen kummallakin viljalla (Taulukko 2). Karitsat söivät ohraa ja kauraa jyvinä enemmän kuin käsiteltyinä. Litistettyä kauraa karitsat vieroksuivat etenkin kasvatuskauden alussa. Käsittely ei vaikuttanut heinän syöntiin $(p=0,80)$ eikä kokonaisenergian $(p=0,40)$ tai kokonaisvalkuaisen saantiin $(p=0,44)$. Syöntitulosten perusteella voidaan sanoa, ettei ohraa eikä kauraa tarvitse prosessoida vieroitetuille karitsoille millään tavalla. Samoin ovat todenneet mm. Fraser ja Ørskov (1974) tutkimuksessaan. 
Ohran ja kauran syönti oli yhtä suurta (800 vs. $797 \mathrm{~g} \mathrm{ka/karitsa/pv).} \mathrm{Ohralla} \mathrm{ruokitut} \mathrm{karitsat}$ söivät heinää $344 \mathrm{~g}$ ka ja kauralla ruokitut vastaavasti $182 \mathrm{~g} \mathrm{ka/karitsa/pv}(\mathrm{p}<0,001)$. Kauran kuitupitoisuus lisäsi rehuannoksen täyttävyyttä ja vähensi täten heinän kuiva-aineen syöntiä. Päinvastoin kuin lypsylehmillä (Heikkilä ym. 1988) rehuannoksen kokonaissyönti oli ohraruokinnalla merkitsevästi suurempi kuin kauraruokinnalla (1162 vs. $990 \mathrm{~g} \mathrm{ka} / \mathrm{karitsa} / \mathrm{pv}, 89$ vs. $78 \mathrm{~g} \mathrm{ka} / \mathrm{kgW}^{0,75}$, $\mathrm{p}<0,001)$.

Taulukko 1. Väkirehujen ja heinän keskimääräinen kemiallinen koostumus, sulavuus ja rehuarvot.

\begin{tabular}{|c|c|c|c|c|c|c|c|}
\hline \multirow{2}{*}{$\begin{array}{l}\text { Rehut } \\
\text { Käsittely }\end{array}$} & \multicolumn{3}{|c|}{ Ohra } & \multicolumn{3}{|c|}{ Kaura } & \multirow{2}{*}{$\frac{\text { Heinä }}{\text { Pitkänä }}$} \\
\hline & Jyvinä & Litistetty & Jauhettu & Jyvinä & Litistetty & Jauhettu & \\
\hline Näytemäärä & 11 & 12 & 11 & 11 & 12 & 11 & 16 \\
\hline \multicolumn{8}{|l|}{ Kuiva-aineessa, g/kg } \\
\hline Orgaaninen aine & 973 & 972 & 973 & 967 & 967 & 962 & 934 \\
\hline Raakavalkuainen & 123 & 129 & 127 & 129 & 131 & 121 & 131 \\
\hline Raakakuitu & 51 & 52 & 49 & 109 & 99 & 103 & 326 \\
\hline \multicolumn{8}{|l|}{ Sulavuus, $\mathrm{g} / \mathrm{kg} \mathrm{ka}^{1)}$} \\
\hline Orgaaninen aine & 794 & 796 & 826 & 682 & 698 & 690 & 680 \\
\hline Raakavalkuainen & 641 & 660 & 771 & 670 & 678 & 666 & 639 \\
\hline D-arvo, g/kg ka & 771 & 770 & 777 & 664 & 682 & 674 & 636 \\
\hline \multicolumn{8}{|l|}{ Rehuarvot/kg ka } \\
\hline $\mathrm{ME}, \mathrm{MJ}$ & 12,4 & 12,5 & 12,6 & 11,4 & 11,7 & 11,5 & 9,6 \\
\hline OIV, g & 89 & 89 & 90 & 79 & 81 & 79 & 77 \\
\hline PVT, $\mathrm{g}$ & -28 & -23 & 25 & -6 & -7 & -14 & 2 \\
\hline
\end{tabular}

Määritetty vain 1. kokeesta, ME: muuntokelpoinen energia, OIV: ohutsuolesta imeytyvät aminohapot, PVT: pötsin valkuaistase.

Taulukko 2. Ohran ja kauran käsittelyn vaikutus karitsan rehunsyöntiin päivässä.

\begin{tabular}{|c|c|c|c|c|c|c|c|c|c|c|}
\hline \multirow{2}{*}{$\begin{array}{l}\text { Ruokinta } \\
\text { Käsittely }\end{array}$} & \multicolumn{3}{|c|}{ Ohra } & \multicolumn{3}{|c|}{ Kaura } & \multirow[b]{2}{*}{ SEM } & \multicolumn{3}{|c|}{ Merkitsevyys } \\
\hline & Jyvinä & Litistetty & Jauhettu & Jyvinä I & Litistetty & Jauhettu & & $\mathrm{p} 1$ & $\mathrm{p} 2$ & p3 \\
\hline Karitsamäärä & 32 & 29 & 31 & 31 & 31 & 31 & & & & \\
\hline Väkirehu, kg ka & 0,84 & 0,79 & 0,77 & 0,82 & 0,79 & 0,78 & 0,078 & 0,88 & 0,03 & 0,76 \\
\hline Heinä, kg ka & 0,36 & 0,32 & 0,35 & 0,15 & 0,21 & 0,19 & 0,026 & $<0,001$ & 0,58 & 0,12 \\
\hline Kokonais-ka, kg & 1,22 & 1,13 & 1,14 & 0,98 & 1,00 & 0,98 & 0,060 & $<0,001$ & 0,14 & 0,13 \\
\hline Kokonais-ME, MJ & 14,13 & 13,09 & 13,26 & 10,97 & 11,29 & 11,03 & 0,798 & $<0,001$ & 0,19 & 0,14 \\
\hline Kokonais-RV, g & 154 & 147 & 148 & 129 & 133 & 128 & 10,0 & $<0,005$ & 0,59 & 0,60 \\
\hline Kokonais-OIV, g & 104 & 96 & 97 & 78 & 80 & 78 & 5,5 & $<0,001$ & 0,22 & 0,15 \\
\hline Kokonais-PVT, g & $-22,5$ & $-16,8$ & $-17,7$ & $-3,0$ & $-3,3$ & $-10,2$ & 4,00 & $<0,005$ & 0,82 & 0,31 \\
\hline
\end{tabular}

Ka: kuiva-aine, ME: muuntokelpoinen energia, RV: raakavalkuainen, OIV: ohutsuolesta imeytyvät aminohapot, PVT: pötsin valkuaistase, SEM: keskiarvon keskivirhe, p1: ohra vs. kaura, p2: jyvinä vs. litistetty + jauhettu, p3: käsittely x viljalaji.

Rehuannoksestaan ohraryhmäläiset saivat muuntokelpoista energiaa merkitsevästi enemmän kuin kauraryhmäläiset (13,5 vs. 11,2 MJ ME/karitsa/pv), samoin OIV-valkuaista (99 vs. $79 \mathrm{~g} / \mathrm{karitsa} / \mathrm{pv}$ ). Painoltaan 25-40-kiloinen ja 250 g päivässä kasvava karitsa tarvitsee ylläpitoonsa ja kasvuunsa keskimäärin 13,9 MJ ME ja 99 g OIV päivässä. Ohralla karitsat tyydyttivät lähes kokonaan energian ja valkuaisen tarpeensa, mutta kauralla ravinnonsaanti jäi noin $20 \%$ alle suomalaisten ruokintasuositusten (Tuori ym. 2000). Pässikaritsat tyydyttivät energian $(13,0$ vs. 11,6 MJ ME, $<<0,001)$ ja valkuaisen tarpeensa (94 vs. $83 \mathrm{~g}$ OIV, $\mathrm{p}<0,001)$ paremmin kuin uuhikaritsat. 
Kasvut. Litistäminen tai jauhaminen eivät parantaneet karitsoiden kasvua, pikemminkin päinvastoin (Taulukko 3). Kun kauraa annettiin jauhettuna, karitsat kasvoivat huonommin $(\mathrm{p}<0,001)$ ja painoivat ennen teurastusta merkitsevästi vähemmän kuin karitsat, joita ruokittiin litistetyllä kauralla tai kauran jyvillä $(\mathrm{p}<0,001)$.

Ohra kasvatti karitsoita kauraa paremmin. Ohralla kasvu oli kokeen aikana keskimäärin 1,6 kg parempi kuin kauralla $(\mathrm{p}<0,01)$. Ohralla karitsat kasvoivat keskimäärin 244 g päivässä ja kauralla vastaavasti $225 \mathrm{~g}(\mathrm{p}<0,01)$. Paras yksittäinen päiväkasvu $387 \mathrm{~g}$ oli karitsalla, joka sai ohraa litistettynä ja huonoin $103 \mathrm{~g}$ karitsalla, jota kasvatettiin litistetyllä kauralla. Pässikaritsat kasvoivat uuhikaritsoita merkitsevästi paremmin (258 vs. $210 \mathrm{~g} / \mathrm{karitsa} / \mathrm{pv}, \mathrm{p}<0,001)$ ja olivat kokeen lopussa keskimäärin 3,8 $\mathrm{kg}$ painavampia kuin uuhikaritsat $(\mathrm{p}<0,001)$.

Karitsoiden terveys. Kokeen aikana jouduttiin lääkitsemään ruokahaluttomuutta vastaan 20 karitsaa. Ruokahaluttomuutta esiintyi lähinnä kokeen loppupuolella noin kuukautta ennen teurastusta. Eniten väkirehuunsa kyllästymistä osoittivat ohraryhmäläiset ja risteytyskaritsat enemmän kuin puhtaat suomenlammaskaritsat. Kokeen aikana 3 risteytyskaritsaa ja 2 puhdasta suomenlammaskaritsaa sairastui virtsakiviin. Näistä vain yksi parantui, muut sairastuneet jouduttiin teurastamaan kesken koetta. Eniten virtsakivitapauksia oli karitsoilla, jotka saivat käsiteltyä ohraa. Voimakas väkirehuruokinta saattaa etenkin vetoisissa kasvatusolosuhteissa aiheuttaa virtsakiviä (Ilivitzky ja Saario 2000, s. 102). Teurastamolla hylättiin lisäksi yksi risteytyspässikaritsan ruho liikakeltaisuuden takia. Keltaisuus viittasi kuparimyrkytykseen. Rehujen kuparipitoisuutta ei tutkittu, mutta on mahdollista, että voimakkaalla väkirehuruokinnalla kuparia kasaantuu maksaan, josta se stressitilanteissa lähtee liikkeelle kohtalokkain seurauksin. Stressiä voi aiheutua jopa normaalista käsittelystä ja kuljetuksesta.

Teurastulokset. Teurastulokset olivat jauhettua kauraryhmää lukuunottamatta hyviä. Koska käsittelytavan vaikutus karitsoiden loppupainoon ei ohralla ollut erilainen kuin kauralla, tehtiin vertailut yli viljalajien. Jauhettua viljaa saaneiden karitsoiden loppupaino oli $1,1 \mathrm{~kg}(\mathrm{p}<0,09)$ ja $3,0 \mathrm{~kg}$ $(\mathrm{p}<0,001)$ pienempi kuin litistettyä viljaa tai jyviä saaneiden karitsoiden loppupaino. Käsittelytavalla ei ollut vaikutusta teuras- $\%$ :iin $(\mathrm{p}=0,86)$.

Ohran ja kauran välinen ero näkyi selvästi teurastuloksissa. Ohralla karitsoiden teuras-\% oli 44,1 ja kauralla 40,1 $(\mathrm{p}<0,001)$. Käytännössä ero tarkoitti sitä, että ohralla saatiin $2,3 \mathrm{~kg}($ s.e. $=0,27 \mathrm{~kg})$ enemmän lihaa per karitsa kuin kauraruokinnalla saman kasvatuskauden aikana $(p<0,001)$. Ohralla ruokittujen karitsoiden ruhonlaatu oli parempi kuin kauralla $(p=0,02)$. Ohraruokinta näkyi myös ruhojen nopeana rasvoittumisena sekä kauraruokintaa suurempana rasvapitoisuutena $(p<0,01)$. Koko tutkimuksen 18 keskirasvaisesta ruhosta 7 oli risteytyskaritsaa ja 11 puhdasta suomenlammaskaritsaa. Tutkimuksen ainoa ylirasvainen ruho oli ohraa jyvinä saanut risteytysuuhikaritsa. Karitsoiden rasvoittuminen näkyi myös munuaisrasvojen määrässä. Ohraryhmäläisillä oli keskimäärin $0,21 \mathrm{~kg}$ enemmän munuaisrasvaa kuin kauraryhmäläisillä. Selvimmin ohran ja kauran väliset erot näkyivät uuhikaritsoilla ja puhtailla suomenlammaskaritsoilla. Voimakkaalla väkirehuruokinnalla on tärkeää, että karitsoiden teuraskypsyys määritetään elopainopunnitusten lisäksi käsin tunnustelemalla ja että karitsat teurastetaan riittävän ajoissa. Näin vältytään liian rasvaisilta ruhoilta. Liika rasvaisuus alentaa teurastiliä ja karkottaa kuluttajia.

Vaikka pässikaritsoiden teuras-\% oli keskimäärin 0,7 \%-yksikköä pienempi kuin uuhikaritsoiden teuras- $\%(p=0,08)$, niin nopeakasvuisempina pässikaritsat tuottivat keskimäärin $1,2 \mathrm{~kg}$ enemmän lihaa kuin uuhikaritsat $(\mathrm{p}<0,001)$.

\section{Johtopäätökset}

Jyvien litistäminen tai jauhaminen ei paranna ohran tai kauran hyväksikäyttöä karitsoilla. Viljan käsittelyn poisjättäminen säästää työtä ja vähentää ruokintakustannuksia. Vieroitettujen lihakaritsoiden ruokintaan suositellaan ohraa jyvinä edellytyksellä, että rehuannoksen kalsium : fosfori -suhde pidetään sopivana $(2,5-3,0: 1)$, ennakolta ehkäistään virtsakivien syntymistä ja että karitsat teurastetaan heti, kun teuraskypsyys on saavutettu. Tutkimus antaa aihetta jatkotutkimuksille, joissa selvitettäisiin ohran osittaista korvaamista kauralla. 
Taulukko 3. Ohra ja kauran käsittelyn vaikutus karitsan paino-, kasvu- ja teurastuloksiin.

\begin{tabular}{|c|c|c|c|c|c|c|c|c|c|c|}
\hline \multirow{2}{*}{$\begin{array}{l}\text { Ruokinta } \\
\text { Käsittely }\end{array}$} & \multicolumn{3}{|c|}{ Ohra } & \multicolumn{3}{|c|}{ Kaura } & \multirow[b]{2}{*}{ SEM } & \multicolumn{3}{|c|}{ Merkitsevyys } \\
\hline & \multicolumn{3}{|c|}{ Jyvinä Litistetty Jauhettu } & \multicolumn{3}{|c|}{ Jyvinä Litistetty Jauhettu } & & \multirow[t]{2}{*}{$\mathrm{p} 1$} & \multirow[t]{2}{*}{$\mathrm{p} 2$} & \multirow[t]{2}{*}{ p3 } \\
\hline Karitsamäärä & 32 & 29 & 31 & 31 & 31 & 31 & & & & \\
\hline Elopaino alussa, $\mathrm{kg}$ & 20,2 & 20,0 & 20,1 & 20,0 & 20,2 & 20,5 & 2,50 & 0,71 & 0,76 & 0,81 \\
\hline Elopaino lopussa, kg & 42,9 & 40,8 & 40,5 & 42,6 & 39,8 & 39,7 & 2,31 & $<0,01$ & $<0,001$ & 0,43 \\
\hline Kasvu, g/eläin/päivä & 260 & 233 & 238 & 247 & 226 & 201 & 10,6 & $<0,01$ & $<0,001$ & 0,30 \\
\hline Ruhonpaino, kg & 19,2 & 18,0 & 17,6 & 16,5 & 16,0 & 15,3 & 1,15 & $<0,001$ & $<0,005$ & 0,57 \\
\hline Teuras- $\%$ & 44,7 & 44,1 & 43,6 & 39,7 & 40,1 & 40,3 & 0,64 & $<0,001$ & 0,66 & 0,21 \\
\hline Munuaisrasvaa, g & 749 & 634 & 566 & 506 & 422 & 405 & 72,9 & $<0,001$ & $<0,01$ & 0,65 \\
\hline \multicolumn{11}{|l|}{ Ruhon laatu ${ }^{1}, \mathrm{kpl}$} \\
\hline Erittäin hyvä & 16 & 12 & 12 & 11 & 9 & 7 & & & & \\
\hline Hyvä & 11 & 13 & 12 & 8 & 11 & 12 & & & & \\
\hline Kohtalainen & 5 & 4 & 7 & 12 & 11 & 11 & & & & \\
\hline Huono & - & - & - & - & - & 1 & & & & \\
\hline \multicolumn{11}{|l|}{ Ruhon rasvaisuus $^{1)}, \mathrm{kpl}$} \\
\hline Ohutrasvainen & 24 & 25 & 27 & 29 & 30 & 31 & & & & \\
\hline Keskirasvainen & 7 & 4 & 4 & 2 & 1 & - & & & & \\
\hline Ylirasvainen & 1 & - & - & - & - & - & & & & \\
\hline
\end{tabular}

SEM: keskiarvon keskivirhe, p1: ohra vs. kaura, p2: jyvinä vs. litistetty + jauhettu, p3: käsittely x viljalaji, ${ }^{1}{ }^{1}$ EUROPluokitusta edeltävä luokitus.

\section{Kirjallisuus}

Fraser, C. \& Ørskov, E.R. 1974. Cereal processing and food utilization by sheep. 1. The effect of processing on utilization of barley by early-weaned lambs. Anim. Prod. 18: 75-83.

Heikkilä, T., Väärtäinen, H. \& Lampila, M. 1988. Barley or oats for dairy cows. In: Proceedings VI World Conference on Animal Production, June 27-July 1, 1985, Helsinki, Finland. p. 336

Ilivitzky, I. \& Saario, E. 2000. Lampaan sairaudet. Lampaan ruokinta ja hoito. Tieto Tuottamaan 90: 91-112.

Owen, J.B. 1976. Sheep Production. Bailliere Tindall, London. 436 pp.

Tuori, M., Kaustell, K., Valaja, J., Aimonen, E., Saarisalo, E. \& Huhtanen, P. 2000. Rehutaulukot ja ruokintasuositukset. Helsinki. 88 pp. 